\title{
Surgical jejunostomy and radiological gastro-jejunostomy tube feeding in children: risks, benefits and nutritional outcomes
}

\author{
Rashmi R. Singh ${ }^{1} \cdot$ Simon Eaton ${ }^{1} \cdot$ Derek J. Roebuck ${ }^{2}$ - Alex M. Barnacle ${ }^{2} \cdot$ Samantha Chippington $^{2}$. \\ Kate M. K. Cross ${ }^{1} \cdot$ Paolo De Coppi ${ }^{1}$. Joe I. Curry ${ }^{1}$
}

Accepted: 9 July 2018 / Published online: 16 July 2018

(c) The Author(s) 2018

\begin{abstract}
Purpose Radiologically inserted gastrojejunal tubes (RGJ) and surgical jejunostomy (SJ) are established modes of jejunal feeding. The aim of the study is to review nutritional outcomes, complications and the practical consideration to enable patients and carers to make informed choice.

Methods Retrospective review of patient notes with a RGJ or SJ in 2010, with detailed follow-up and review of the literature. Results Both RGJ and SJ are reliable modes to provide stable enteral nutrition. Both have complications and their own associated limitations.

Conclusions The choice has to be tailored to the individual patient, the social care available, the inherent medical disease and risk/benefit of repeated anaesthetic and radiation exposure. RGJ and SJ are important tools for nutritional management that achieve and maintain growth in a complex group of children. The risk and benefits should be reviewed for each individual patient.
\end{abstract}

Keywords Jejunostomy $\cdot$ Gastro-jejunostomy tube $\cdot$ Nutritional outcome

Rashmi R. Singh

rashmi.singh@ucl.ac.uk

Simon Eaton

s.eaton@ucl.ac.uk

Derek J. Roebuck

derek.roebuck@gosh.nhs.uk

Alex M. Barnacle

Alex.Barnacle@gosh.nhs.uk

Samantha Chippington

samantha.chippington@gosh.nhs.uk

Kate M. K. Cross

kate.cross@gosh.nhs.uk

Paolo De Coppi

paolo.decoppi@gosh.nhs.uk

Joe I. Curry

Joe.Curry@gosh.nhs.uk

1 Department of Paediatric Surgery, UCL Great Ormond Street Institute of Child Health and Great Ormond Street Hospital for Children, London, UK

2 Department of Radiology, UCL Great Ormond Street Institute of Child Health and Great Ormond Street Hospital for Children, London, UK

\section{Introduction}

In children with gastrointestinal dysfunction, jejunal access can be used for enteral feeding. The inability to tolerate gastric feeding can be due to a variety of reasons including, gastro-oesophageal reflux, gastric dysmotility and poor gastric compliance [1]. Historically, these children received a surgical jejunostomy (SJ). Radiologically inserted gastrojejunal tubes (RGJ) are now more commonly used than surgical jejunostomy $[2,3]$. Our aim was to understand whether this change in practice provides additional benefit for the patient/ family or institution.

We reviewed outcomes in children with surgical feeding jejunostomy and radiologically inserted trans-gastric jejunal feeding tubes at our institute.

\section{Methods}

After appropriate institutional audit approval (no. 1035), a retrospective review to identify patients who had a jejunostomy in the year 2010 was performed. At the commencement of the study, we wanted to have children with at least 
3 years of follow-up. We reviewed the hospital coding database and identified seventy-eight children who had a new jejunostomy in 2010. Of these, 29 children were excluded as detailed note review revealed that they either did not have the primary jejunostomy in 2010 or the jejunostomy was a part of laparotomy to act as a de-functioning stoma. Data were extracted on outcomes from those with a 'de novo' RGJ or SJ from clinic and discharge letters, admission records, imaging procedures and inpatient stay records. Procedures were performed by consultant interventional radiologists or paediatric surgeons, or by trainees at the specialist registrar level under direct supervision of a consultant. In our institute, the RGJ and SJ devices used are approved (CE marked) and marketed in the UK and EU but is not FDA approved. The RGJ had initial 9-Fr Freka gastrostomy devices converted to 15-Fr under general anaesthesia. Thereafter, 9-Fr coaxial jejunal extension was inserted under fluoroscopic guidance. This was done by pushing the extension tube (loaded with its stiffening wire) through the pylorus and then advancing it over the wire until it reached the jejunum. If this was not possible a shaped angiographic catheter and guidewire was used to access the jejunum, and the jejunal catheter advanced over the guidewire. Balloon gastrostomy tubes were removed (without general anaesthesia) and a shaped angiographic catheter and guidewire were used to access the jejunum through the gastrostomy. A balloon GJ device Kimberley Clark or AMT was then inserted over the guidewire [4].

We collected data for RGJ and SJ patients with respect to demography, neurological diagnosis, indication, previous anti-reflux surgery, complications, hospital admission, further surgery, removal of the device and followup. We reviewed their weights before and after RGJ or $\mathrm{SJ}$ as an outcome measure. Weight-for-age $Z$ scores
(Standard deviation scores) were calculated using the LMS (Lambda-Mu-Sigma) growth add-in [5] for Microsoft Excel 2010 (Microsoft Corporation) program, using British 1990 reference data [6]. A $Z$ score of 0 is equivalent to 50th centile, -1 to 16 th centile and -2 to 2 nd centile. Malnourished children were defined as weight $Z$ score of -2 or less. Growth over time was assessed as mean change in $Z$ score per year by Multilevel modelling using MIWin 2.36 (Centre for Multilevel Modelling, University of Bristol, Bristol, $\mathrm{UK})$.

\section{Results}

Forty-eight children had a jejunostomy for feeding in the year 2010 and they were included in the study. In the RGJ group, thirty-one children had pre-existing gastrostomy, while 5 had a new Freka gastrostomy inserted through which the jejunal extension was passed (under fluoroscopic guidance). Demographic data are presented in Table 1. More than half of the patients who received either RGJ or SJ were neurologically impaired (58\% and $67 \%$ respectively). Indications for jejunal feeding are listed in Table 2. In $83 \%$ of SJ and $69 \%$ of RGJ, it was recurrent gastro-oesophageal reflux (GOR). This was confirmed by either a contrast study or $\mathrm{pH}$ study. The majority of children in each group had a previous anti-reflux operation, $n=19 / 36$ (53\%) in RGJ and $n=6 / 12$ $(50 \%)$ in SJ (Table 3).

The type of surgical jejunostomy depended on the choice of the operating surgeon and the disease aetiology. Most of the surgeons preferred formation of Roux-en-Y jejunostomy $(n=7)$, the others were Witzel tunnel $(n=4)$ and laparoscopy assisted $(n=1)$. The initial tube was a Malecot 14-Fr catheter that was converted to a balloon button gastrostomy
Table 1 Demographic data of children receiving a jejunostomy in 2010

\begin{tabular}{lll}
\hline & RGJ $(n=36)$ & SJ $(n=12)$ \\
\hline Age median (range) in months & $37(5-202)$ & $41(6-213)$ \\
Sex & 17 males/19 females & 11 males/1 female \\
Neurological impairment & $21(58 \%)$ & $8(67 \%)$ \\
$\begin{array}{l}\text { Other indications_gastric dysmotil- } \\
\text { ity associated with }\end{array}$ & Metabolic disorder 3 & Oesophageal atresia 1 \\
& Oesophageal atresia 2 & Gut failure due to \\
& & immune dysregula- \\
& tion 1 \\
& Failure to thrive 2 & Metabolic disorder 1 \\
& Cardiac disorder 2 & Endocrine disorder 1 \\
& Malignant disorder 2 & \\
& Endocrine disorder 1 & \\
& Dystrophic epidermolysis bullosa 1 & \\
& Short bowel syndrome after resection for & \\
& multiple atresia 1 & \\
& Severe combined immune deficiency 1 & \\
&
\end{tabular}


Table 2 Indications for jejunal feeding

\begin{tabular}{lll}
\hline & RGJ $(n=36)$ & SJ $(n=12)$ \\
\hline Recurrent GOR & $25(69 \%)$ & $10(83 \%)$ \\
$\begin{array}{l}\text { Not tolerating gastric feeds } \\
\begin{array}{c}\text { Duodenal obstruction due to: } \\
\text { Multiple intestinal strictures }\end{array}\end{array}$ & $11(31 \%)$ & 0 \\
$\begin{array}{c}\text { Long-gap oesophageal atresia: } \\
\text { gastric pull-up + SJ }\end{array}$ & 0 & $1(8 \%)$ \\
\hline
\end{tabular}

GOR gastro-oesophageal reflux

at 6 weeks. The Witzel tunnel was performed over a duodenal feeding tube of size ranging from 6 to $9 \mathrm{Fr}$.

There were four major complications in each of the RGJ $(11 \%)$ and SJ (33\%) groups. Four buried bumpers in RGJ, while two cases of bowel obstruction (one due to colonic volvulus and ventral hernia at fundoplication site in a Rouxen-Y SJ, and the other intussusception with small bowel volvulus in a Witzel tunnel SJ) and two cases of stenosis/atresia at skin level needing re-fashioning of SJ.

The children who received a SJ had various rare disease pathologies. One child had multiple intestinal abscesses as a part of global immune deficiency. He had multiple resections and anastomoses of the small bowel during formation of SJ. There was stenosis of the jejunostomy later as a part of the disease process and it required revision. Another child with congenital myopathy and oesophageal stricture developed stenosis of the stoma mouth and needed re-fashioning of the jejunostomy.

The RGJ group needed tube replacement at a median of 1.3 (0-20) times/year. Balloon RGJ devices every 4-6 months, and the 15-Fr/9-Fr Freka system every 1-2 years as a planned procedure. Fifteen children needed further 18 operations (Table 3). In 20/36 children, RGJ was removed after 0.8 years $(0.1-2.4)$. Four were fed orally, three oral with gastrostomy, five via gastrostomy alone, five had fundoplication plus gastrostomy and three converted to SJ.

Twelve children had SJ, which was a part of laparotomy in 5/12. Four (33\%) had SJ after RGJ. SJ was reversed in one orally fed child.

Nutritional outcome was measured as weight $\mathrm{Z}$ scores over time. RGJ children were on average slightly underweight (mean $-1.4 \pm$ standard error $0.26 Z$ scores) at jejunostomy, with $4 / 36$ (11\%) of children malnourished (less than $-2 Z$ scores $)$. RGJ children grew stably $(+0.4 \pm 0.1$ $Z$ scores per year follow-up, $p=0.58$ ).SJ children were on average significantly malnourished $(-3.7 \pm 0.99 \mathrm{Z}$ scores $)$ at the time of jejunostomy, with $4 / 12(33 \%)$ of children less than $-2 Z$ scores. Growth significantly improved following $\mathrm{SJ}(+1.2 \pm 0.3 Z$ scores/year follow-up, $p<0.0001)$ (Fig. 1).

RGJ were followed up for a median of $2.4(0.18-3.4)$ years, while SJ were followed up for a median of $1.8(0-3.5)$ years.

\section{Discussion}

Complex, neurologically impaired children have a range of feeding difficulties from uncoordinated swallow to GORD and gastrointestinal dysmotility. Once maximal medical therapy has failed, management options include gastric tube feeding, anti-reflux procedure, jejunal feeding or a combination. The rate of recurrent GORD after an anti-reflux procedure is between 10 and 14\% [7-9]. For these patients, a re-do fundoplication has a high failure rate of $20-30 \%$ [10, 11]. Jejunostomy feeding has been previously reported and may be preferred over a redo fundoplication [3, 12]. Long-term outcomes following SJ and RGJ have been compared in a
Table 3 Previous surgery and further surgery after a RGJ or SJ

\begin{tabular}{lll}
\hline & RGJ $(n=36)$ & SJ $(n=12)$ \\
\hline Previous surgery $n(\%)$ & Fundoplication + G 15 (42) & Fundoplication + G 5 (42) \\
& Gastrostomy 12 (33) & Gastrojejunostomy 4 (33) \\
& Fundoplication + revision + G 4 (11) & Laparotomy 3 (25) \\
& None 5 (14) & Gastrostomy 3 (25) \\
& & Fundoplication + revision twice + G 1 (8) \\
& & None 1 (8) \\
Further surgery $n(\%)$ & Revision fundoplication + G 6 (17) & Re-fashioning 2 (17) \\
& SJ 4 (11) & Laparotomy (bowel obstruction) 2 (17) \\
& Removal of buried bumper 3 (8) & \\
& Fundoplication + G 2 (6) & \\
& Revision of G 3 (8) & \\
& $(n=3$ had more than 1 procedure) & \\
\hline
\end{tabular}

$G$ gastrostomy 


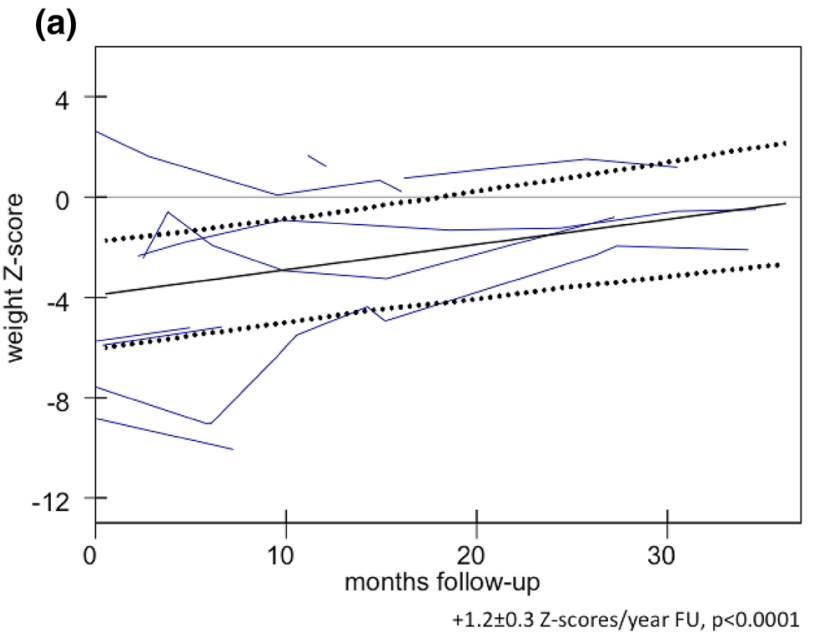

(b)

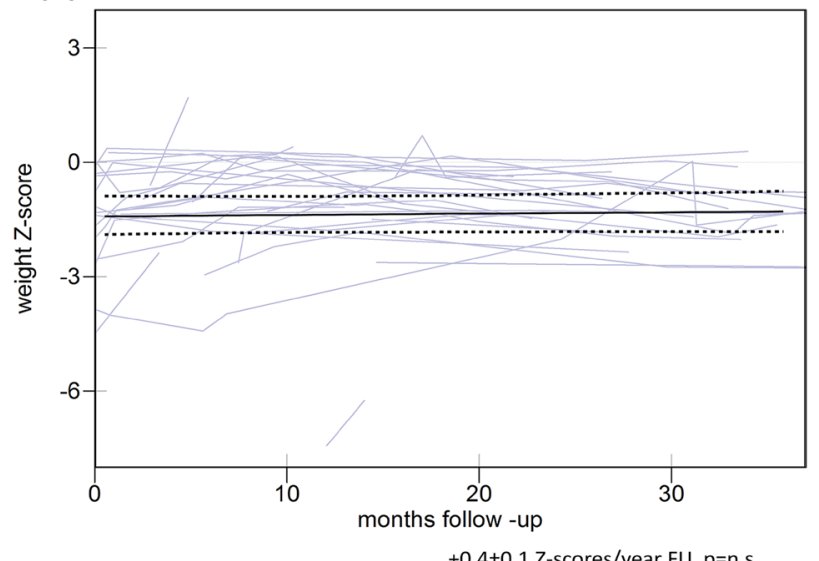

Fig. 1 a Weight $Z$ scores for children after SJ. b Weight $Z$ scores for children after RGJ. Individual patients are shown together with the mean trend line with $95 \%$ confidence intervals of the mean, analysed by multilevel modelling

previous series [1]. They concluded that SJ are more stable feeding access devices with fewer complications.

There is a reported association of buried bumpers and gastro-jejunal tubes [13] (when the gastric component of the tube is inserted as a percutaneous technique). This can be due to the reluctance of the carer to advance the gastro-jejunal device, for fear of dislodging the jejunal component. Due to the presence of the jejunal tube, the carers are advised to only advance the gastrostomy tube and not to rotate it. Often the jejunal component of the RGJ is routinely replaced and the gastrostomy device remains in situ for a longer duration than intended.

SJ has been reported to have a high complication rate. Williams et al. reported major complication rate of $37 \%$ [14] and Smith et al. reported a major complication rate of $31 \%$ [15] with Roux-en-Y SJ. Taylor et al. reported volvulus around Roux-en-Y SJ in 5 out of 25 patients (20\% complication rate) [16]. Egnell et al. reported 33\% re-operation rate after SJ for small bowel obstruction, perforation, wound rupture tube dislodgement and tube leak [17]. At our institute, the surgical technique has evolved over time, with Rouxen-Y SJ, having a shorter stem of the Roux-en-Y limb, thus minimizing the risk of volvulus.

There has been reported increased association of intussusception and jejunal perforation with RGJ in children less than $6 \mathrm{~kg}$ of weight and 6 months of age [18]. We did not experience this. However, for children $<10 \mathrm{~kg}$, we prefer a 15-Fr/9-Fr Freka system over the thick and relatively stiff 16-Fr Kimberley Clark device.

Determining nutritional benefit from RGJ or SJ in this complex group of children is challenging. The use of weight $Z$ scores before and after the jejunostomy insertion gives an objective measure of the probable effect of the intervention on nutrition. As the underlying disease progresses, becomes stable or regresses, there may be an effect on absorption of nutrients from the gut and maintenance of nutrition. Changes in $Z$ scores are multi-factorial and include changes in feeding regime, formulas used, and other background general illness. The patients who had an RGJ were slightly underweight at the start and maintained stable weight gain (manifested as stable $Z$ score). The patients who had a SJ, on the other hand, were significantly malnourished at $\mathrm{SJ}$ insertion and their growth improved significantly (significant increase in weight $Z$ score). Rather than just the effect of the jejunostomy, this result reflects the fact that patients who had a SJ had the jejunostomy after progressive deterioration of the primary disease and failure of escalating nutritional interventions. Given our data, we conclude that both RGJ and SJ are effective as they have a stabilizing effect on reliable delivery of nutrition.

Another aspect that requires consideration in the choice of procedure to be offered is the radiation dose received, not just at the initial RGJ insertion, but also each time the tube is replaced. In a sample of 110 consecutive patients (not the same patients as the primary study population, as data were not available), the median radiation dose-area product (DAP) for a change of RGJ tube was $7 \mu \mathrm{Gy} \cdot \mathrm{m}^{2}(0-622$ $\mu \mathrm{Gy} \cdot \mathrm{m}^{2}$, Fig. 2) with a median fluoroscopy time of $25 \mathrm{~s}$ ( $0 \mathrm{~s}-40 \mathrm{~min})$. There is no clear consensus regarding the additional cumulative lifetime risk of radiation to patients [19].

The average cost of insertion of an SJ at our institution is around $£ 11,000$ as the procedure involves a general anaesthetic, theatre time and inpatient stay of several days (although several SJ patients had SJ insertion together with another abdominal procedure), whereas the average cost associated with a day case admission and insertion of RGJ in the radiology suite is around $£ 590$ (data obtained from the hospital costings department). The recurrent costs associated with each is also likely to be different: RGJ will require changing in interventional radiology approximately every 6 months, whereas 


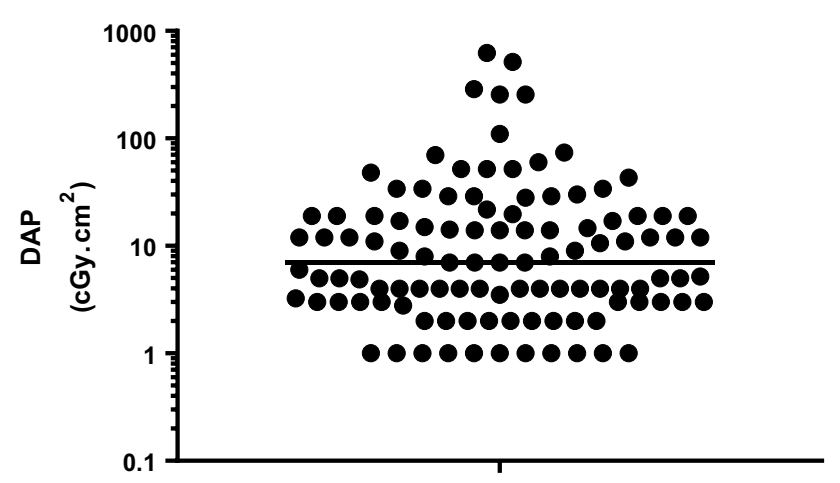

Fig. 2 Dose-area product (DAP) for 110 children having an RGJ tube change (Horizontal line denotes the median DAP)

the SJ tube can be replaced in an outpatient appointment. A full cost-effectiveness analysis, including the cost of complications, however, was not undertaken as part of the current study.

In adults, laparoscopic jejunostomy has been reported in 299 patients with low rate of post-operative small bowel obstruction [20]. Laparoscopic Roux-en-Y jejunostomy has been reported in five children one of whom required dilatation for stomal stenosis [21]. Esposito et al. have described laparoscopic-assisted jejunostomy formation in ten neurologically impaired children [22]. One patient $(10 \%)$ died 1 year after the procedure of unknown causes. The other complications were four $(40 \%)$ peristomal hernias, two (20\%) device dislocation and one peristomal granuloma.

Direct percutaneous endoscopic jejunostomy has been reported in five children with good results [23]. However, in a large series of 286 adult patients, the success rate was $68 \%$ and the procedure was associated with a complication rate of $10 \%$ [24]. Recently percutaneous laparoscopic endoscopic jejunostomy has been reported in sixteen children [25]. They had two complications (12.5\%) of small bowel volvulus, which required surgical intervention.

The effect of repeated hospital admission for RGJ tube replacement with inadvertent displacement on the quality of life of the patient and caregivers has not been studied in the adult or paediatric literature. We have also become aware of some families' difficulty in sourcing RGJ tube placement regularlywhen their child transitions to adult care. This, in our experience, has been the reason for families choosing to have an SJ over a RGJ. A formal quality of life assessment for the patient and caregivers is much needed.

Although there are papers citing increased morbidity after a RGJ [26, 27], this remains a feasible alternative in the fragile patient with compromised respiratory function due to recurrent aspiration [28].

\section{Conclusions}

To conclude, our data suggest that both RGJ and SJ are reliable modes to provide stable enteral nutrition. The choice of the procedure and device has to be tailored to the individual patient, the social care available, the inherent medical disease and risk/benefit of repeated anaesthetic and radiation exposure.

This study is not intended to directly compare SJ and RGJ, as this group of patients represent a heterogeneous population who often have had a trial of nasogastric, gastric, naso-jejunal, RGJ feeding before becoming significantly malnourished, thus resorting to a SJ. Although RGJs require more device maintenance than SJ, they have less significant complications. RGJ can be used as a temporary stabilizing measure after failed anti-reflux operations in the neurologically impaired. Insertion or replacement through an existing gastrostomy under radiological guidance obviates the need for a general anaesthetic in most cases.

A consistently high DAP for tube changes in an individual patient might be a relative indication to convert from a RGJ strategy to SJ. The cost and inconvenience associated with tube replacement and hospital admission is another important consideration. This information should be presented to the family while counselling for the choice of jejunal tube.

RGJ and SJ are important tools for nutritional management that achieve and maintain growth in a complex group of children. The risk and benefits should be reviewed for each individual patient.

\section{Compliance with ethical standards}

Conflict of interest The authors declare that they have no conflict of interest.

Ethical approval All procedures performed in this study were in accordance with the ethical standards of our institution and with the 1964 Helsinki declaration and its later amendments.

Informed consent Informed consent was obtained from all individual participants included in the study.

Open Access This article is distributed under the terms of the Creative Commons Attribution 4.0 International License (http://creativeco mmons.org/licenses/by/4.0/), which permits unrestricted use, distribution, and reproduction in any medium, provided you give appropriate credit to the original author(s) and the source, provide a link to the Creative Commons license, and indicate if changes were made.

\section{References}

1. Raval MV, Phillips JD (2006) Optimal enteral feeding in children with gastric dysfunction: surgical jejunostomy vs image-guided gastrojejunal tube placement. J Pediatr Surg 41(10):1679-1682 
2. Hoffer EK, Cosgrove JM, Levin DQ, Herskowitz MM, Sclafani SJ (1999) Radiologic gastrojejunostomy and percutaneous endoscopic gastrostomy: a prospective, randomized comparison. J Vasc Interv Radiol 10(4):413-420

3. Wales PW, Diamond IR, Dutta S, Muraca S, Chait P, Connolly B, Langer JC (2002) Fundoplication and gastrostomy versus imageguided gastrojejunal tube for enteral feeding in neurologically impaired children with gastroesophageal reflux. J Pediatr Surg 37(3):407-412

4. Roebuck DJ, McLaren CA (2011) Gastrointestinal intervention in children. Pediatric radiology 41(1):27-41. https://doi.org/10.1007/ s00247-010-1699-2

5. Cole TJ, Pan H (2011) LMSgrowth, a Microsoft Excel add-in to access growth references based on the LMS method. Version 2.74

6. Cole TJ, Freeman JV, Preece MA (1998) British 1990 growth reference centiles for weight, height, body mass index and head circumference fitted by maximum penalized likelihood. Stat Med 17(4):407-429

7. Lopez-Fernandez S, Hernandez F, Hernandez-Martin S, Dominguez E, Ortiz R, De La Torre C, Martinez L, Tovar JA (2014) Failed Nissen fundoplication in children: causes and management. Eur J Pediatr Surg 24(1):79-82. https://doi. org/10.1055/s-0033-1351664

8. Rossi V, Mazzola C, Leonelli L, Gandullia P, Arrigo S, Pedemonte M, Schiaffino MC, Mancardi M, Sacco O, Disma NM, Zanaboni C, Montobbio G, Barabino A, Mattioli G (2016) Longterm outcome and need of re-operation in gastro-esophageal reflux surgery in children. Pediatr Surg Int 32(3):277-283. https://doi. org/10.1007/s00383-015-3853-2

9. Wheatley MJ, Coran AG, Wesley JR, Oldham KT, Turnage RH (1991) Redo fundoplication in infants and children with recurrent gastroesophageal reflux. J Pediatr Surg 26(7):758-761

10. Kimber C, Kiely EM, Spitz L (1998) The failure rate of surgery for gastro-oesophageal reflux. J Pediatr Surg 33(1):64-66

11. Furnee EJ, Draaisma WA, Broeders IA, Smout AJ, Gooszen HG (2008) Surgical reintervention after antireflux surgery for gastroesophageal reflux disease: a prospective cohort study in 130 patients. Arch Surg (Chicago, Ill: 1960) 143 (3):267-274. https ://doi.org/10.1001/archsurg.2007.50 (discussion 274)

12. Albanese CT, Towbin RB, Ulman I, Lewis J, Smith SD (1993) Percutaneous gastrojejunostomy versus Nissen fundoplication for enteral feeding of the neurologically impaired child with gastroesophageal reflux. J Pediatr 123(3):371-375

13. Goring J, Lawson A, Godse A (2016) Are PEGJs a risk factor for the buried bumper syndrome? J Pediatr Surg 51(2):257-259. https ://doi.org/10.1016/j.jpedsurg.2015.10.072

14. Williams AR, Borsellino A, Sugarman ID, Crabbe DC (2007) Roux-en-Y feeding jejunostomy in infants and children. Eur $\mathrm{J}$ Pediatr Surg 17(1):29-33. https://doi.org/10.1055/s-2007-964929

15. Smith D, Soucy $P$ (1996) Complications of long-term jejunostomy in children. J Pediatr Surg 31(6):787-790

16. Taylor JA, Ryckman FC (2010) Management of small bowel volvulus around feeding Roux-en-Y limbs. Pediatr Surg Int 26(4):439-442. https://doi.org/10.1007/s00383-010-2553-1
17. Egnell C, Eksborg S, Grahnquist L (2014) Jejunostomy enteral feeding in children: outcome and safety. JPEN J Parenter Enteral Nutr 38(5):631-636. https://doi.org/10.1177/0148607113489832

18. Morse J, Baird R, Muchantef K, Levesque D, Morinville V, Puligandla PS (2017) Gastrojejunostomy tube complications-a single center experience and systematic review. J Pediatr Surg 52(5):726-733. https://doi.org/10.1016/j.jpedsurg.2017.01.026

19. Andronikou S (2017) Letting go of what we believe about radiation and the risk of cancer in children. Pediatr Radiol 47(1):113 115. https://doi.org/10.1007/s00247-016-3697-5

20. Young MT, Troung H, Gebhart A, Shih A, Nguyen NT (2016) Outcomes of laparoscopic feeding jejunostomy tube placement in 299 patients. Surg Endosc 30(1):126-131. https://doi.org/10.1007/ s00464-015-4171-4

21. Neuman HB, Phillips JD (2005) Laparoscopic Roux-en-Y feeding jejunostomy: a new minimally invasive surgical procedure for permanent feeding access in children with gastric dysfunction. J Laparoendosc Adv Surg Tech Part A 15(1):71-74. https://doi. org/10.1089/lap.2005.15.71

22. Esposito C, Alicchio F, Escolino M, Ascione G, Settimi A (2013) [Laparoscopy-assisted jejunostomy in neurological patients with chronic malnutrition and GERD. Technical considerations and analysis of the results]. La Pediatria medica e chirurgica: Med Surg Pediatr 35(3):125-129. https://doi.org/10.4081/pmc.2013.45

23. Virnig DJ, Frech EJ, Delegge MH, Fang JC (2008) Direct percutaneous endoscopic jejunostomy: a case series in pediatric patients. Gastrointest Endosc 67(6):984-987. https://doi.org/10.1016/j. gie.2007.11.008

24. Maple JT, Petersen BT, Baron TH, Gostout CJ, Wong Kee Song LM, Buttar NS (2005) Direct percutaneous endoscopic jejunostomy: outcomes in 307 consecutive attempts. Am J Gastroenterol 100(12):2681-2688. https://doi.org/10.111 1/j.1572-0241.2005.00334.x

25. Belsha D, Thomson M, Dass DR, Lindley R, Marven S (2016) Assessment of the safety and efficacy of percutaneous laparoscopic endoscopic jejunostomy (PLEJ). J Pediatr Surg 51(3):513518. https://doi.org/10.1016/j.jpedsurg.2015.11.023

26. Fortunato JE, Darbari A, Mitchell SE, Thompson RE, Cuffari C (2005) The limitations of gastro-jejunal (G-J) feeding tubes in children: a 9-year pediatric hospital database analysis. Am J Gastroenterol 100(1):186-189. https://doi.org/10.111 $1 / \mathrm{j} .1572-0241.2005 .40893 . \mathrm{x}$

27. Godbole P, Margabanthu G, Crabbe DC, Thomas A, Puntis JW, Abel G, Arthur RJ, Stringer MD (2002) Limitations and uses of gastrojejunal feeding tubes. Arch Dis Child 86(2):134-137

28. Karabulut R, Turkyilmaz Z, Sonmez K, Oktar SO, Kaya C, Kokurcan A, Oncu F, Basaklar AC (2015) A very feasible alternative in patients with feeding difficulties from gastrostomy: jejunal tube advanced through the gastrostomy. Afr J Paediatr Surg: AJPS 12(2):119-121. https://doi.org/10.4103/0189-6725.160353 